\title{
我国层控多金属矿床的铅同位素 特征及其矿床成因意义
}

\author{
陈 好 寿
}

本文对我国不同地区、不同时代的 20 多个层控多金属矿床的近 200 个铅同位素测定数 据 ${ }^{*[1-3]}$, 用各种模式进行了计算、作图和对比研究后, 从铅同位素角度探讨了成矿时代、矿床成 因、物质来源、成矿过程,以及找矿勘探等问题.

\section{一、我国层控矿床的铅同位美特征}

在 20 多个矿床中, 其铅同位素组成有如下几种类型（见图 1):（1）铅同位素组成变化不 大, 即在一个矿床或矿区中铅同位素组成相对稳定, 并含放射成因铅低, 落于正常铅演化曲线 之上或其附近,基本上属正常铅,称“正常型”; (2) 变化范围虽不很大(也有较大的), 但含放射 成因铅很高,远远偏离演化曲线, 全属明显异常铅, 称“异常型”; (3)铅同位素组成变化很大, 从 含放射成因铅很低或较低到含放射成因铅很高, 是正常铅与异常铅混合的结果, 称“混合型”。

除第二类外, 每个矿床中所含的最小放射成因铅, 其同位素组成 (如 $\mathrm{Pb}^{206} / \mathrm{Pb}^{204}$ 比值) 随矿 床或围岩年龄增加而减少. 多数矿床用所含的最小放射成因铅计算的模式年龄与其围岩的年 龄(或来源物质年龄)基本一致或十分接近.

\section{二、铅同位素的矿床成因意义讨论}

1. 成矿时代及来源物质年龄的确定从铅同位素特征可以看出, 在层控矿床中,除少数 外,多数矿床的铅或全属稳定的正常铅,或含有放射成因铅相对低的“正常铅”组分（最小放射 成因铅). 根据这些正常铅或最小放射成因铅的同位素组成, 选用合适的模式和参数完全可以 计算出有地质意义的“模式年龄”。

本文采用两阶段演化模式进行年龄计算 ${ }^{[4]}$,结果多数是比较满意的.特别是前寒武纪的样 品, 多数能代表成矿时代或来源物质的年龄, 如高板河、白云鄂博等矿区. 在古生代地层中, 也有很多矿区计算的模式年龄是满意的. 如大西沟、矾口(泥盆系)、辑安(寒武系)，其最大模 式年龄与地层时代一致。辽宁关门山铅锌矿赋存于震旦系白云岩中，铅模式年龄接近 20 亿 年,相当于下伏辽河群的时代,表明铅来自古老基底. 湖南白云铺铅锌矿的模式年龄大于 5 亿 年,比围岩要老,也代表来源物质的年龄. 即该矿的铅很可能来自寒武纪地层.

2.矿床成因问题从铅同位素特征和模式年龄计算结果可以看出, 许多层控矿床的铅 都是异常铅与正常铅的混合产物.若用其中最小放射成因铅计算的模式年龄与围岩一致,表明

本文1980 年 6 月 24 日收到.

* 数据分别由地质部宜昌地矿研究所、中国科学院贵䧂地球化学研究所、地质部云南省地质研究所和长春地质学院等 单位测定, 大多数数据引自有关文献, 笔者作了重新处理和新的解释. 


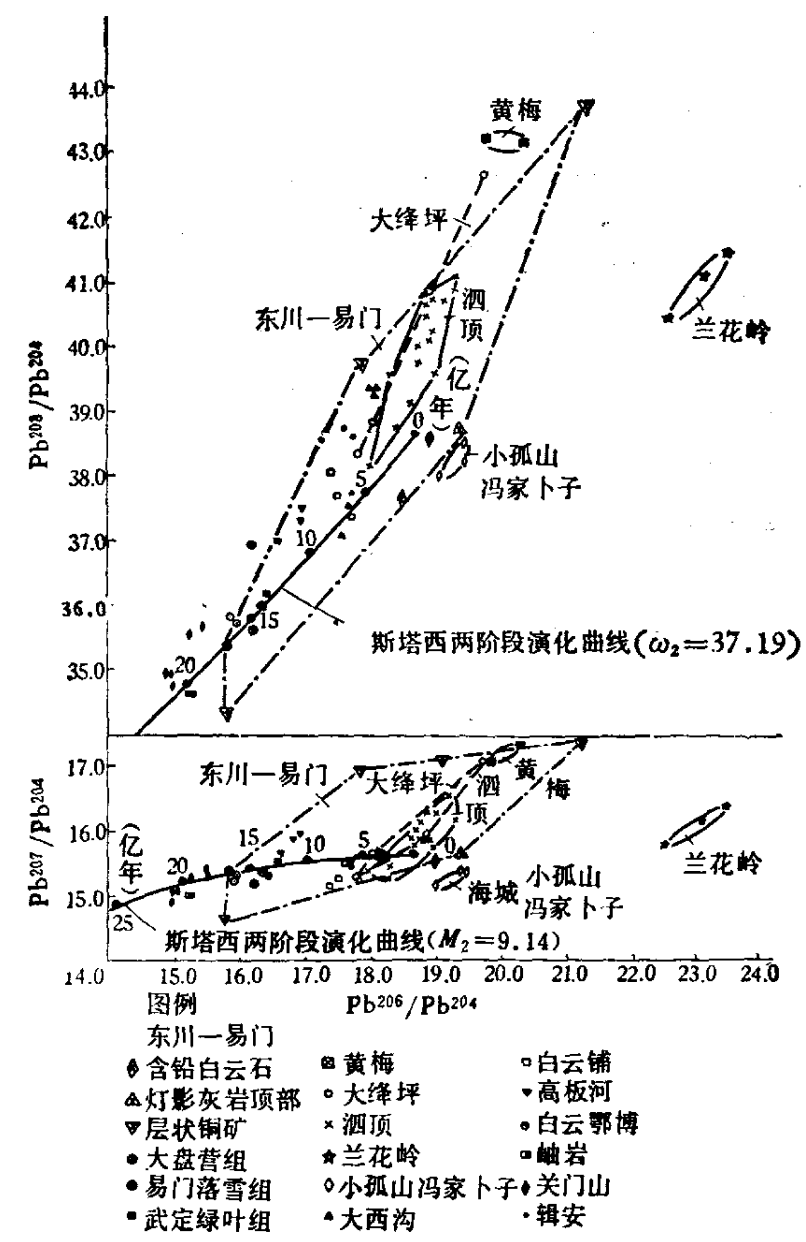

图 1 我国层控矿床部分铅同位素坐标图

表示有三种主要类型：（1）正常型—接近正常铅, 落于演化曲线附近; (2) 异常 型——明显异常铅, 远离演化曲线; (3)混合型一一变化大, 为正常铅与异常铅的混合

最初为同生沉积矿床或成岩期矿床. 如基本属正常铅, 其数据相对稳定, 仅有个别稍有偏离 (测定误差除外)，表明这些矿床仅遭到了轻微的改造，属沉积一轻微改造层控矿床，例如高板 河、大西沟等铅锌矿; 如果铅同位素组成变化很大,同一矿床中两种铅(正常铅和异常铅)都有, 则可能是强烈改造的结果，即属沉积一强烈改造矿床。如矾口、泗顶、白云鄂博、青城子,花垣等 矿,除层状矿体外,还有一些呈脉状的矿体.有的矿床从整个矿体来看是层状或似层状,但从矿 石结构构造来看仍是呈脉状的,富含放射成因铅，很多是改造或再造的结果; 全为异常铅或虽 为正常铅,但计算的模式年龄明显与围岩不一致者, 或为后成矿床,或为沉积一强烈改造矿床, 如黄梅、关门山、白云铺以及辽河群和昆阳群中某些矿床等等. 所以，铅同位素的变化特征有 可能反映沉积作用和沉积改造的程度,作为矿床成因的示踪剂.

3.物质来源问题就铅而论 (可以推论 $\mathrm{Cu} 、 \mathrm{Fe} 、 \mathrm{Zn}$ 等其它金属)，如含稳定的正常铅， 一般是来自深部地壳或上地幔, 并在成矿过程中没有受到上部地壳物质的污染, 或在长距离搬 运中铅同位素已均匀化, 总之是单一来源的. 许多火山沉积一一改造的矿床, 其铅的来源可能 是通过海底火山喷发作用从深部带来的. 关门山、白云铺的铅来自下伏老地层,其同位素组成 是稳定的、正常的。其最初来源仍可能是深部地壳或上地幔,或在变质作用过程中发生了铅同 位素均匀化,在再动员过程中铅同位素未发生变化; 如含有变化明显的铅同位素组成, 显然是

第 10 期

科学 通报 
有多种来源或深部来源的铅受到上部来源铅的污染; 如全为放射成因铅很高的异常铅,一般是 来自上部地壳岩石, 或基底岩石或围岩甚至上覆年轻地层等等. 因为上地壳比起下地壳和上 地幔, 其 $\mathrm{U} / \mathrm{Pb} 、 \mathrm{Th} / \mathrm{Pb}$ 比值要高得多,从中派生出来的铅也是富放射成因的 ${ }^{[5,6]}$.

4. 成矿过程或成矿阶段问题：矿床中如含有显著变化的铅同位素组成, 表明铅是来自 具不同 $\mu\left(\mathrm{U}^{238} / \mathrm{Pb}^{231}\right)$ 或 $\omega\left(\mathrm{Th}^{232} / \mathrm{Pb}^{204}\right)$ 值的源区, 也是多阶段成矿的结果. 根据铅同位素特征 可以了解先后不同阶段之间的相互关系. 很多矿区, 层状矿体与脉状矿体、大型主矿体与周围 小矿体 (卫星矿床)之间同位素组成各不相同。有的差别很大, 表明不同来源或相隔时间很长; 有的差别不大, 表明同源或相隔时间短. 如前所述, 许多沉积一一改造矿床和后成矿休是在沉 积阶段形成层状矿体或矿源层，之后在长期的地质作用之下，经过地下热水的作用将层状矿体 中的铅运移出来, 再在裂隙、断层或层间裂隙等有利构造环境中沉淀成矿. 在这过程中, 如果没 有另一来源(如地壳岩石中)的铅的混人或时间间隔不长, 那么后期形成的矿体其铅同位素组 成与其来源铅应是相似的. 相反, 如在再沉淀过程中有外来铅(从不同 $\mu$ 值源区演化的铅)的加 人,则铅同位素组成会发生显著的变化. 辽宁辽河群中其些矿床的铅同位素资料表明,沱沟、苇 山、青城子、东胜、小孤山、兰花岭等矿床其铅同位素组成各有特点, 相互之间差别很大, 显然是 不同来源的结果, 也是明显的不同阶段的产物. 但在青城子和东胜矿区内部, 层状矿体和切层 断裂与层间复合矿体之间,其同位素组成稍有差异,但不明显,显然它们是同源的,切层断裂矿 体的铅可能来自层状矿体.

5.找矿勘探评价问题各个矿床都有自己特征的铅同位素组成. 不同地区（矿区或成 矿区)都有自己特征的铅同位素“分配模式”。而这些特征的组成和 “分配模式” 常常与矿床规 模有非常密切的联系. 因此,铅同位素分析可以作为找矿勘探和对矿床进行评价的重要指示.

表 1 我国几种主要类型层控矿床的成因、金属来源、成矿机理及铅同位素特征

\begin{tabular}{|c|c|c|c|c|}
\hline 因 & 初始来源 & 成 矿 机 理 & 铅同位素特征 & 典型矿沐 \\
\hline $\begin{array}{c}\text { 同生沉积 } \\
\text { (成岩)-轻微 } \\
\text { 改造矿床 }\end{array}$ & $\begin{array}{l}\text { 上地 幔 } \\
\text { 或 } \\
\text { 深部地壳 }\end{array}$ & $\begin{array}{l}\text { 多与火山作用有关（火山或海底 } \\
\text { 火山-沉积一轻微改造） }\end{array}$ & $\begin{array}{c}\text { 正 常 型 } \\
\text { 正常铅, 模式年龄与围 } \\
\text { 岩时代基本一致 }\end{array}$ & $\begin{array}{l}\text { 大西沟 } \\
\text { 辑 安 } \\
\text { 高板河 }\end{array}$ \\
\hline $\begin{array}{l}\text { 沉积-强烈 } \\
\text { 改造矿佅 }\end{array}$ & $\begin{array}{l}\text { 上地幔或深部地壳来源 } \\
\text { 加上部地壳来源(多来源) }\end{array}$ & $\begin{array}{l}\text { 沉积-再动员-再沉积, 形成层状 } \\
\text { 加脉状矿床在变运再沉积过程中加 } \\
\text { 人上部地壳铅 } \\
\text { (多阶段成矿) }\end{array}$ & $\begin{array}{l}\quad \text { 混 合 型 } \\
\text { 正常铅加异常铅 } \\
\text { 最小放射成因铅的模式 } \\
\text { 年龄与围岩时代一致或接 } \\
\text { 近 }\end{array}$ & $\begin{array}{l}\text { 酒 顶 } \\
\text { 矾 } \\
\text { 花 垣 }\end{array}$ \\
\hline $\begin{array}{l}\text { 后成或再 } \\
\text { 造矿床 }\end{array}$ & $\begin{array}{l}\text { (1) 来自上部地壳岩石 } \\
\text { 一基底岩石或上稪年轻地 } \\
\text { 层 } \\
\text { (2) 来自上部地壳岩 } \\
\text { 石, 但最初来源仍为上地 } \\
\text { 幔或下地売 }\end{array}$ & $\begin{array}{l}\text { 铅从高度放射成因的上部地壳岩 } \\
\text { 石中迁移出来在有利环境中沉积成 } \\
\text { 矿, 多与雨水、地下水的深部环流作 } \\
\text { 用有关 } \\
\text { 在搬运过程中铅同位素末遭到改 } \\
\text { 变 }\end{array}$ & $\begin{array}{c}\text { 异 常 型 } \\
\text { 含高放射成因的异常铅 } \\
\text { 正常 型 } \\
\text { 正常铅, 但模式年龄与 } \\
\text { 围岩不一致 } \\
\text { (a) >围岩. 来自老地 } \\
\text { 层 } \\
\text { (b) <围岩. 来自年轻 } \\
\text { 地层 }\end{array}$ & $\begin{array}{l}\text { 黄 梅 } \\
\text { 小孤山 } \\
\text { 兰花岭 }\end{array}$ \\
\hline
\end{tabular}


如上所述,许多矿区的大型整合矿床为正常铅, 而附近的小矿为异常铅或相对含放射成因铅低 的正常铅. 如关门山、青城子都是. 因此, 在类似地区放射成因铅相对低的正常铅可作为寻找 大型整合矿床的标志; 也可以用某一时代 (模式年龄) 作为寻找某种类型矿床的标志. 如在美 国落基山区, 16 亿年的铅是前寒武纪大型矿床一一铅、锌、铜、镍矿床的标志, 28 亿年的铅对 找金矿有利等, 在我国南方昆阳群、东北辽河群中要注意寻找 20 亿年和 15-16 亿年关门山 式、东川式大型矿床.

当然也有另外的情况,早期同生沉积的正常铅不具工业意义,经过后期改造成为含放射成 因铅高的工业矿体. 那么, 在这样的地区, 铅同位素组变化大可能作为找寻沉积一一强烈改造 型大型矿床的标志, 如泗顶式、矾口式等; 美国密西西比式大型铅锌矿为典型的含放射成因铅 特高的异常铅. 因此, 高放射成因的异常铅是寻找密西西比式大型矿床的标志. 在我国云 贵、桂北、累北地区, 特别是寒武系和泥盆系碳酸岩、砂页岩中都有可能找到沉积一强烈改造型 大型矿床.

根据上述讨论，我们将我国层控矿床的几种主要类型 (不是全部) 的成因、金属来源、成 矿机理及铅同位素特征归纳如表 1 .

\section{三、结 语}

综上所述, 可以得出如下几点结论性意见:

（1）我国层控矿床中铅同位素组成可分为正常型、异常型和混合型三种. 正常型和混合 型中最小放射成因铅随矿床或围岩年龄的增加而同位素组成 $\left(\mathrm{Pb}^{206} / \mathrm{Pb}^{204} 、 \mathrm{~Pb}^{207} / \mathrm{Pb}^{234}\right.$ 和 $\mathrm{Pb}^{208}$ ) $\mathrm{Pb}^{204}$ 比值)有规律地逐渐减少，其模式年龄一般能反映围岩时代或来源物质的年龄.

（2）层控矿床中三种类型的铅可能分别代表不同来源. 正常铅其初始来源多半来自深部 地壳或上地幔, 异常铅来自上部地壳岩石,混合型铅是多来源多阶段演化的结果.

（3）铅同位素可作为矿床成因和成矿过程的指示剂. 不同的铅同位素特征代表不同的成 因类型.正常铅是同生或成岩时的铅,计算的模式年龄与围岩一致,表明最初属同生沉积矿床. 混合型铅代表沉积——改造型矿床。异常铅 (包括 B 型异常铅) 代表后成矿床或沉积——强 烈改造矿床. 原生沉积的层状矿床与后生改造的脉状矿床之间同位素组成的差异性反映它们 铅来源的异同和成矿阶段间隔的长短. 很多矿床显示出后者的铅是从前者来的或在前者的基 础上加入放射成因铅的结果.

（4）有的矿区显示出大型整合矿床为正常铅,小矿、脉状矿为异常铅. 如在同一成矿区或 相似地区再找到新的正常铅, 则有可能找到新的大型整合矿床; 但在铅同位素高度异常的地区 也要注意寻找密西西比式的大型矿床,在铅同位素组成变化大 (含混合型铅) 的地区要注意找 大型沉积一改造型矿床.

致谢：本工作是在涂光炽教授有关我国层控矿床成因研究及其分类思想的指导下进行的. 在本文写作 过程中又得到涂教授的热情鼓励和支持,并详细审阅初稿, 在此谨表谢意.

[1] 张翼翼、邱纯一、毛存孝、洪阿实、霍卫国,地质科学, 1964, 2: 182-187.

[2]陈好寿,全国同位素地质会议文集(第三集),地质出版社, 1979, 3-13.

[3] 陈好寿,铅同位素地质研究的基本问题,地质出版社, 1979, 209-214.

[4] Stacey, J. S. \& Kramers, J. D., Earth and Planet. Sci. Letters, 26 (1975), 207-221.

[5] Faure, G., Principles of Isotope Geology, 1977, 227-263.

[6] Канасевич Э. Р., Радиометрическое датирование, 1973, 116-170. 